\title{
A comparison of methods of phenotypic and genotypic fingerprinting of Exophiala dermatitidis isolated from sputum samples of patients with cystic fibrosis
}

\author{
P.-M. RATH, K.-D. MÜLLER, HEIDE DERMOUMI and R. ANSORG \\ Institut für Medizinische Mikrobiologie, Universität-GH Essen, Hufelandstrasse 55, 45147 Essen, Germany
}

\begin{abstract}
Phenotypic and genotypic characteristics of 11 strains of Exophiala dermatitidis were investigated. Ten strains (including three reference strains) were isolated from sputum samples of six patients with cystic fibrosis (CF) in Germany, and one reference strain was isolated from a patient with phaeohyphomycosis in Japan. The strains showed differences in their ability to assimilate sorbitol, palatinose, rhamnose, gluconate and melezitose, leading to the differentiation of seven auxotypes. The IC30 of amphotericin $B$, and ketoconazole and itraconazole, respectively, indicated susceptibility, whereas the IC30 of fluconazole and 5-fluorocytosine indicated resistance in all strains. Protein patterns in SDS-PAGE revealed no major differences. The glycoconjugate patterns distinguished the Japanese strain from the other strains. Cluster analysis of whole-cell fatty acid methyl ester (FAME) profiles with the Microbial Identification System (MIS) revealed two major clusters separating a reference strain and the Japanese strain from the other strains. Analysis of patterns resulting from random amplification of polymorphic DNA (RAPD) with two arbitrary primers showed four genotypes. Comparison of the results revealed no agreement between the different fingerprinting methods, except the separation of the Japanese strain from the European CF strains. As the results of assimilation tests seem to vary between different laboratories, the analysis of FAME profiles and RAPD analysis are recommended for typing $E$. dermatitidis.
\end{abstract}

\section{Introduction}

The black yeast Exophiala dermatitidis (Kano) de Hoog 1977 (synonym Wangiella dermatitidis McGinnis) is a dematiaceous hyphomycete with a synanamorph yeast form. It is an important aetiological agent in phaeohyphomycosis [1]. Phaeohyphomycosis is a group of a subcutaneous and systemic infections caused by fungi with melanin-like pigment in the wall of hyphae [2]. The agents are numerous and varied in their generic classification; however, most of them belong to the dematiaceous hyphomycetes. The most important agent of cystic lesions is Exophiala jeansel$m e i$. Cerebral infections are most often caused by Xylohypha (Cladosporium) trichoides. E. dermatitidis causes subcutaneous and deep infections and is neurotropic [2]. From 1934 to 1992, 37 cases of phaeohyphomycosis due to $E$. dermatitidis were described with a mortality rate of $48 \%$ [1]. It has also

Received 24 Oct. 1996; revised version accepted 1 Feb. 1997.

Corresponding author: Dr P-M. Rath. been cultured from sputum samples in $9-16 \%$ of European patients with cystic fibrosis (CF) $[3,4]$. However, the clinical significance of the isolation of $E$. dermatitidis in these patients remains unknown. In one published case, a clinically relevant pulmonary infection of a patient with CF was suspected, based on serological findings and the response to treatment with itraconazole [5].

Very few data are available on phenotypic and genotypic characteristics of the yeast that would allow detailed epidemiological investigations [6-8]. In one study, ribotyping and random amplification of polymorphic DNA (RAPD) were used to investigate 21 strains of this species, leading to differentiation of two genotypes by ribotyping, and seven genotypes by RAPD analysis [6].

To gain more information about subtyping, 11 isolates were compared by the following phenotypic and genotypic methods: (i) assimilation of carbon sources; (ii) susceptibility to antimycotic agents; (iii) protein patterns; (iv) glycoconjugate patterns; (v) profiles of 
long-chain fatty acids; and (vi) patterns of randomly amplified polymorphic DNA (RAPD).

\section{Materials and methods}

\section{Strains}

Seven strains of $E$. dermatitidis were isolated from sputum samples of three patients with CF at the Department of Paediatrics in Essen, Germany, on Sabouraud Dextrose Agar (Unipath). Identification was based on the typical macroscopic and microscopic morphology, growth at $40^{\circ} \mathrm{C}$, evidence of melanin synthesis, production of urease and inability to utilise nitrate and nitrite $[6,9]$. Strains were stored at $-70^{\circ} \mathrm{C}$ in Protect Bacterial Preservers (TSC, Heywood Lanes) until use. Four reference strains, including three strains from three patients with $\mathrm{CF}$, were obtained from the Centraalbureau voor Schimmelcultures (CBS), Barn, Netherlands. The sources of strains are listed in Table 1.

\section{Assimilation tests}

To determine the assimilation of different carbon substrates, the API ID 32C system (API bioMérieux, Marcy-l'Étoile, France) originally developed for the identification of yeasts was used. The system was used according to the manufacturer's instructions, with some modifications: a larger inoculum $\left(c .10^{6} \mathrm{cfu} / \mathrm{ml}\right)$ and the strips were incubated at $28^{\circ} \mathrm{C}$ for 5 days. To verify reproducibility, the test was performed three times, with different subcultures of the strains.

\section{Susceptibility testing}

Susceptibility testing was performed with amphotericin B (Squibb-von Heyden, Munich, Germany), 5-fluorocytosine (Hoffmann-La Roche, Grenzach-Wyhlen, Germany), ketoconazole (Janssen, Neuss, Germany), itraconazole (Janssen) and fluconazole (Pfizer, Karlsruhe, Germany). The minimum concentrations that inhibited growth to a level of $30 \%$ of the growth control (IC30) were determined by the microplate method as described previously [10]. Buffered Yeastnitrogen Broth (Difco), supplemented with glucose $1 \%$ and asparagine $0.15 \%$ was used as the growth medium. Breakpoints were fixed for amphotericin B, ketoconazole and itraconazole at $2 \mathrm{mg} / \mathrm{L}$, for 5 -fluorocytosine at $80 \mathrm{mg} / \mathrm{L}$ and for fluconazole at $16 \mathrm{mg} / \mathrm{L}[10,11]$. All tests were done in duplicate.

\section{Protein and glycoconjugate separation by SDS- PAGE}

Strains were cultured on Sabouraud Glucose Agar (Becton Dickinson BBL, Heidelberg, Germany) for 4 days at $36^{\circ} \mathrm{C}$. Cells (c. 3-4 g) from three agar plates (diameter $9.5 \mathrm{~cm}$ ) were harvested in $10 \mathrm{ml}$ of $\mathrm{NaCl}$ $0.9 \%$ solution, washed twice in $\mathrm{NaCl}$ solution and once in Tris-EDTA buffer $(100 \mathrm{mM}$ Tris- $\mathrm{HCl}, \mathrm{pH} 7.5,1 \mathrm{mM}$ EDTA). Cells were suspended in $5 \mathrm{ml}$ of cold TrisEDTA buffer containing $1 \mathrm{mM}$ phenylmethylsulphonyl fluoride (PMSF) and pepstatin (Boehringer Mannheim, Germany) $5 \mu \mathrm{g} / \mathrm{ml}$.

Glass beads (0.45-0.7 mm diameter) were added, $2 \mathrm{~g} / \mathrm{ml}$ of cell suspension, and the mixture was vortex mixed at maximum speed three times for $5 \mathrm{~min}$ each, with intermittent cooling on ice, in a L 46 Vortexer (Gesellschaft für Laborbedarf, Würzburg, Germany). The procedure resulted in c. $90 \%$ cell disruption as determined by microscopy. The suspensions were centrifuged for $5 \mathrm{~min}$ at $5000 \mathrm{~g}$ and $4^{\circ} \mathrm{C}$. The supernates were centrifuged for $20 \mathrm{~min}$ at $10000 \mathrm{~g}$ and $4^{\circ} \mathrm{C}$. The clear supernates were harvested and stored at $-70^{\circ} \mathrm{C}$ until further use. Their protein content was determined by the Modified Lowry Protein Assay (Pierce, Rockford, IL, USA).

Samples were boiled for $5 \mathrm{~min}$ in sample buffer (125 mM Tris- $\mathrm{HCl}, \mathrm{pH} 6.8$, SDS 4\%, glycerol 20\%, 2mercaptoethanol 10\%). Proteins were separated by electrophoresis in SDS-polyacrylamide $7.5 \%$ and $12 \%$ gels [12]. Gels were stained with Coomassie Blue $\mathrm{R}$ (Serva, Heidelberg, Germany).

For glycan detection, the boiled extracts were separated in an SDS-polyacrylamide $7.5 \%$ gel. The glycoproteins were transferred to nitrocellulose sheets $(0.45-\mu \mathrm{m}$ pore size, Schleicher and Schuell, Dassel, Germany) in transfer buffer (25 mM Tris, $\mathrm{pH} 8.2-8.4$,

Table 1. Sources of E. dermatitidis strains

\begin{tabular}{cllll}
\hline Strain no. & Source/Synonym & Locality & Underlying disease & Specimen \\
\hline 1 & Patient A & Germany & Cystic fibrosis & Sputum \\
2 & Patient B & Germany & Cystic fibrosis & Sputum \\
3 & Patient B & Germany & Cystic fibrosis & Sputum \\
4 & Patient C & Germany & Cystic fibrosis & Sputum \\
5 & Patient C & Germany & Cystic fibrosis & Sputum \\
6 & Patient C & Germany & Cystic fibrosis & Sputum \\
7 & Patient C & Germany & Cystic fibrosis & Sputum \\
8 & CBS 149.90 & Germany & Cystic fibrosis & Sputum \\
9 & CBS 154.90 & Germany & Cystic fibrosis & Sputum \\
10 & CBS 552.90 & Germany & Cystic fibrosis & Sputum \\
11 & CBS 207.35 & Japan & Facial phacohyphomycosis & Skin \\
\hline
\end{tabular}

CBS, Centraalbureau voor Schimmelcultures. 
$192 \mathrm{mM}$ glycine, methanol 15\%, SDS $0.05 \%$ ) at $400 \mathrm{~mA}$ constant current for $30 \mathrm{~min}$ with icewater cooling, in a Hoefer transphor chamber (Hoefer Scientific Instruments, San Francisco, CA, USA). The glycoconjugates were detected on nitrocellulose sheets with the DIG Glycan Detection Kit (Boehringer Mannheim, Germany). To verify reproducibility, all experiments were performed twice.

\section{Fatty acid methyl ester (FAME) profile analysis}

Isolates were analysed with the Microbiol Identification System (MIS) of MIDI (Microbial ID, Inc., Newark, DE, USA) [13]. Cultivation was made on Sabouraud Glucose Agar for 5 days at $28^{\circ} \mathrm{C}$. Approximately $150 \mathrm{mg}$ of cells were used for each sample. Samples were saponified with $\mathrm{NaOH} 15 \% \mathrm{w} / \mathrm{v}$ in aqueous methanol $50 \% \mathrm{v} / \mathrm{v}$, methylated with methanolic $\mathrm{HCl}$, extracted in hexane/methyl-t-butyl-ether, and cleaned in $\mathrm{NaOH}$ saturated with $\mathrm{NaCl}$, according to the manufacturers' instructions [14].

The organic layers were removed and injected into a gas chromatographic system (Hewlett Packard Co, Avondale, PA, USA), consisting of a model 5890 Series II Plus gas chromatograph, equipped with a 5\% phenylmethyl silicone capillary column (Hewlett Packard Co., Ultra 2, $25 \mathrm{~m} \times 0.2 \mathrm{~mm} \times 0.33 \mu \mathrm{m})$, a split/splitless capillary inlet system, a flame ionisation detector, a model 6890 injector with automatic sampler and a model Vectra XU 5/90 C computer with HP 3365 Series II ChemStation (version 3.34). MIDI's Sherlock library generation software (version 1.06) and MIS Standard Library (version 3.8) for fungi were used for peak identification, species identification and dendrogram generation by cluster analysis [15]. The dendrograms provided both relative and absolute information about the strains. Strains that were joined at lower levels were more closely related than those that were joined at higher levels. The Euclidean distance (ED) between the strains is the distance between two points in n-dimensional space, calculated on the basis of the Pythagorean theorem. For bacterial strains, an ED 6-10 represents the same species, $<6$ represents the same subspecies and $\leqslant 2.5$ the same strain [16]. To show its reproducibility, the analysis was performed three times with different subcultures.

\section{RAPD analysis}

Strains were cultured on Sabouraud Glucose Agar for $48 \mathrm{~h}$ at $36^{\circ} \mathrm{C}$. Two $10-\mu$ l loops full of culture material were suspended in $500 \mu \mathrm{l}$ of lysis buffer (10 mM Tris$\mathrm{HCl}, \mathrm{pH} 7.8,100$ mM EDTA). Lauroylsarcosine (Serva) $2 \%$ and proteinase $\mathrm{K}$ (Boehringer Mannheim) $1 \mathrm{mg} / \mathrm{ml}$ were added. The suspensions were incubated at $60^{\circ} \mathrm{C}$ for $1 \mathrm{~h}$ followed by a boiling step for $5 \mathrm{~min}$. Thereafter, a phenol-chloroform (Roti-Phenol, Carl Roth, Germany) extraction was performed twice. DNA was precipitated by adding 0.2 volumes of $10 \mathrm{M}$ ammonium acetate and 2 volumes of ethanol $96 \%$. After a centrifugation step for $5 \mathrm{~min}$ at $14000 \mathrm{~g}$, the pellets were washed in $500 \mu \mathrm{l}$ of ethanol $70 \%$ and dried in a desiccator for $10 \mathrm{~min}$. Subsequently, the DNA was suspended in $200 \mu \mathrm{l}$ of TE buffer $(10 \mathrm{mM}$ Tris- $\mathrm{HCl}$, $\mathrm{pH} 7.5,1 \mathrm{~mm}$ EDTA), and $50 \mu \mathrm{l}$ of RNAase A (10 mg/ $\mathrm{ml}$; Boehringer Mannheim) were added. The mixtures were incubated at $37^{\circ} \mathrm{C}$ for $3 \mathrm{~h}$. The DNA concentrations were determined with the DNA DipStick (Invitrogen, San Diego, CA, USA).

The primers used for polymerase chain reaction (PCR) were synthesised by Pharmacia (Freiburg i. B., Germany): primer 1 (R108, 5'-GTATTGCCCT-3') was described previously by Aufauvre-Brown et al. [17]. The sequence of primer 2 (5'-GCTGGTGG-3') was published by Loudon et al. [18]. Both primers have been used successfully for fingerprinting Aspergillus fumigatus $[12,17,18]$. DNA amplification with the single primers and a combination of the two primers was performed under non-stringent conditions ( $3 \mathrm{mM} \mathrm{MgCl}, 35^{\circ} \mathrm{C}$ annealing temperature), as described previously [12]. All experiments were done in duplicate.

\section{Results}

The $11 E$. dermatitidis strains differed neither in macroscopic nor in microscopic morphology. In the API 32C identification system, all strains assimilated sucrose, arabinose, maltose, trehalose, 2-keto-gluconate, D-xylose, glycerol, mannitol, glucose and sorbose. As shown in Table 2, differences were found in the assimilation of sorbitol (five strains positive), palatinose (one strain positive), rhamnose (one strain positive), gluconate (one strain positive) and melezitose

Table 2. Assimilation profiles (API ID 32C) of 11 E. dermatitidis strains

\begin{tabular}{|c|c|c|c|c|c|c|c|c|c|c|c|}
\hline \multirow[b]{2}{*}{ Substrate } & \multicolumn{11}{|c|}{ Strain no. } \\
\hline & 1 & 2 & 3 & 4 & 5 & 6 & 7 & 8 & 9 & 10 & 11 \\
\hline Sorbitol & - & + & - & + & + & - & - & + & - & + & - \\
\hline Palatinose & - & - & - & - & - & - & - & + & - & - & - \\
\hline Rhamnose & - & - & - & - & - & - & - & - & - & - & + \\
\hline Gluconate & - & - & - & - & - & - & + & - & - & - & - \\
\hline Melezitose & + & + & + & + & - & + & + & + & - & + & - \\
\hline Auxotype & I & II & I & II & III & I & IV & V & VI & II & VII \\
\hline
\end{tabular}

+ , assimilation; - , no assimilation. 
(eight strains positive). On the basis of the assimilation of these five substrates, seven auxotypes (1-VII) were found.

In susceptibility testing, all strains showed identical IC30 values with amphotericin $\mathrm{B}(<0.125 \mathrm{mg} / \mathrm{L})$, 5fluorocytosine $(>100 \mathrm{mg} / \mathrm{L})$, ketoconazole $(0.25 \mathrm{mg}$ / L) and itraconazole $(0.125-0.25 \mathrm{mg} / \mathrm{L})$, whereas the IC30 values for fluconazole were $8 \mathrm{mg} / \mathrm{L}$ in strain no. 11 , and 16 to $>32 \mathrm{mg} / \mathrm{L}$ in the other strains.

Analysis of the protein patterns revealed no major differences. All isolates showed major bands in the range of $110,105,87,75,53,48 / 47,38,33 / 32,27$ and $17 / 18 \mathrm{kDa}$.

Analysis of the glycoconjugate patterns revealed major bands in the range $190,170,100,82,72$ and $58 \mathrm{kDa}$ in all isolates (Fig. 1). However, isolate no. 11 (the Japanese strain) showed an additional band at $160 \mathrm{kDa}$, not seen in the other strains.

The MIS system, which is based on FAME profiles, identified all strains correctly as $E$. dermatitidis. In the cluster analysis, strains 8 and 11 were clearly separated from the other strains (Fig. 2). In addition, the second cluster was separated into a sub-cluster with two strains (nos. 7 and 10) and a sub-cluster with seven strains (nos. 1-6 and 9). Therefore, three FAME chemotypes (A, B-1 and B-2) were found.

In the RAPD analysis with primer 1, strains nos. 1-7, 9 and 10, showed identical patterns with major bands at 1300, 1100, 920, 770 and 740 bp (Fig. 3). However, strains 8 and 11 were different. With primer 2, isolates 1-7 showed identical patterns, again. Strains nos. 9 and 10 were different from nos. $1-7$. This primer also differentiated strains 8 and 11 from each other and

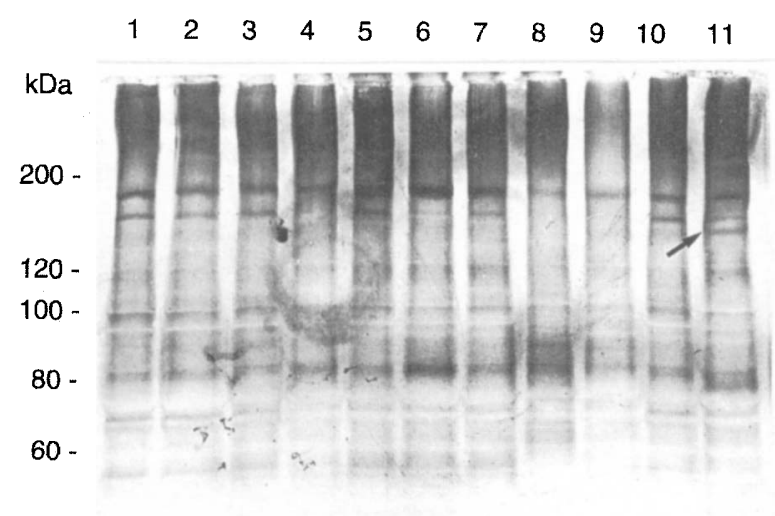

Fig. 1. Glycoconjugate patterns of 11 E. dermatitidis strains. Lysates containing $20 \mu \mathrm{g}$ of protein/lane were applied on to an SDS-PAGE $7.5 \%$ gel. The approximate mol. wts of marker proteins are indicated on the left side. The numbers above the lanes indicate the strain numbers (see Table 1). The band at $160 \mathrm{kDa}$ in strain no. 11 is indicated by an arrow.

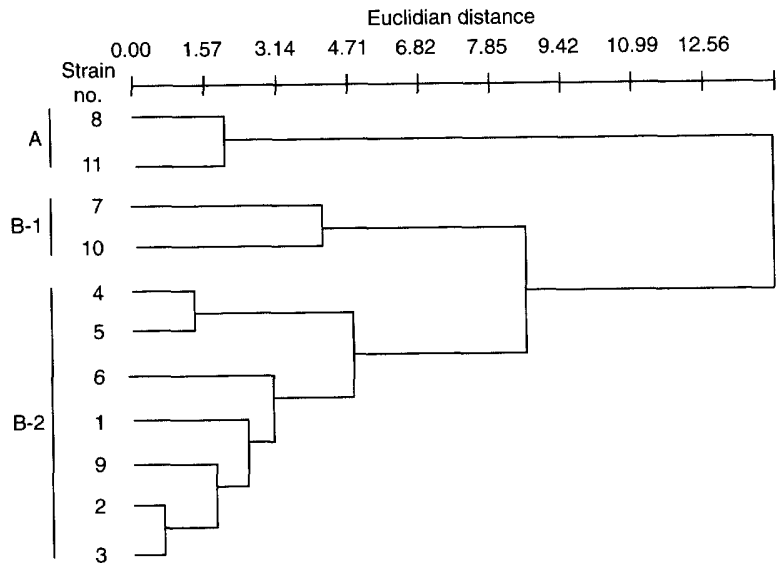

Fig. 2. Cluster analysis of FAME profiles of $11 \mathrm{E}$. dermatitidis strains showing two major clusters (A and B). Cluster B is subdivided into B-1 and B-2. The numbers indicate the strain numbers (see Table 1 ).
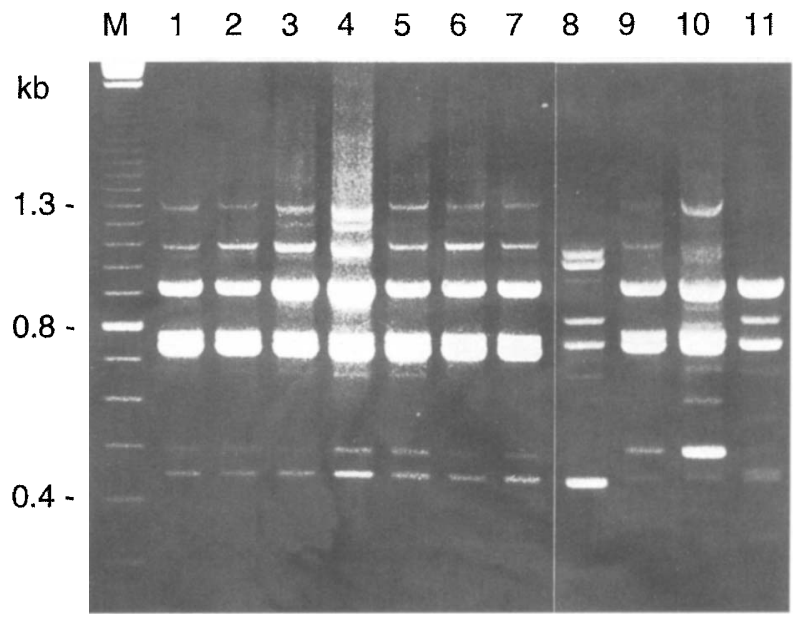

Fig. 3. RAPD patterns of 11 E. dermatitidis strains generated by primer 1 . After amplification, the PCR products were separated in agarose $1.6 \%$ gels, stained with ethidium bromide and photographed under UV light. A 100-bp marker (M) was run in parallel. The numbers above the lanes indicate the strain numbers (see Table 1).

from the remaining strains (Fig. 4). Combining the two primers resulted in non-reproducible patterns.

Comparing the six typing methods, the protein patterns had no discriminatory power. The glycoconjugate patterns distinguished between the Japanese strain (strain II) and the European strains. The FAME analysis revealed three chemotypes and the RAPD analysis revealed four genotypes. The assimilation tests differentiated seven auxotypes, and even differed between isolates obtained from the same patients (Table 3 ).

\section{Discussion}

The techniques used in this study showed differences in the capacity to differentiate between $11 \mathrm{E}$. dermatitidis strains. The analysis of Coomassie Blue-stained protein patterns, as well as the results of susceptibility testing, 


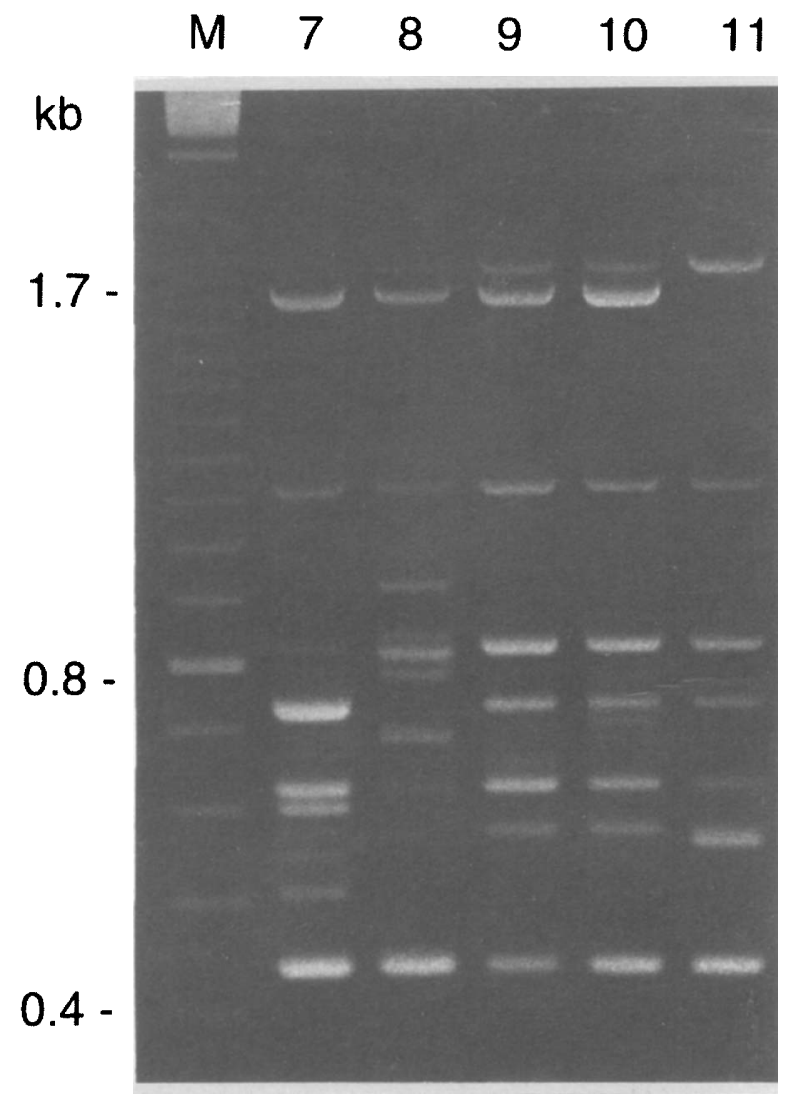

Fig. 4. RAPD patterns of five $E$. dermatitidis strains, generated by primer 2 . The numbers above the lanes indicate the strain numbers (see Table 1).

were insufficient for strain differentiation. The results of susceptibility testing were in agreement with data previously published $[4,19]$. All isolates were resistant to 5-fluorocytosine and fluconazole, but susceptible to amphotericin B, ketoconazole and itraconazole. In glycoconjugate patterns, the Japanese strain showed differences from the European strains.

The MIS system, based on cell-bound fatty acid methyl ester (FAME) analysis by gas chromatography, was established for the identification of bacterial species. A library for fungi is also included in the software. With this software, the system identified all strains correctly as E. dermatitidis. In addition, the system has been used successfully for fingerprinting and clustering bacterial strains, e.g., methicillinresistant strains of Staphylococcus aureus [20]. Cluster analysis of FAME profiles by MIS of the $E$. dermatitidis isolates discriminated a CF reference strain (no. 8) and the epidemiologically unrelated Japanese strain (no. 11) from the other CF strains, which were further sub-clustered into two clusters. In bacterial strains, an ED of 6-10 represents the same species but different chemotypes and an ED of 10-25 represents different species [16]. However, whether this is also true for eukaryotic cells like yeasts is not clear. In one study [21], strains of Candida albicans and $C$. tropicalis were clearly separated from $C$. lusitaniae strains with an ED $>10$ [21]. As the ED (c. 12) between the two major clusters (A and B) was nearer to 10 than to 25 in the present study on $E$. dermatitidis, the result was interpreted as borderline.

The most discriminating typing was obtained by assimilation tests. However, the results of the assimilation tests differ from previous data. Espinel-Ingroff et al. [22] and Haase et al. [3] demonstrated that the absence of melezitose assimilation is a useful criterion for identifying $E$. dermatitidis. In contrast, BlaschkeHellmessen et al. [4] included only those strains that assimilated melezitose in their study. In this study, with the same assay as Haase et al. [3] eight strains were found to assimilate melezitose. Three of these strains were found to be melezitose negative by Haase et al. [3]. The results of assimilation assays may differ because of different technical procedures, e.g., inoculum, temperature and duration of incubation, which were not described in previous studies [3,4]. Interestingly, different auxotypes were found in the same patients. As assimilation patterns were totally reproducible, the results indicate that phenotypically different strains occurred in one host or that phenotypic switching occurred.

In previous studies with DNA-DNA hybridisation and

Table 3. Results of phenotypic and genotypic fingerprinting of $11 \mathrm{E}$. dermatitidis strains

\begin{tabular}{|c|c|c|c|c|c|}
\hline \multirow{2}{*}{$\begin{array}{l}\text { Strain } \\
\text { no. }\end{array}$} & \multirow{2}{*}{$\begin{array}{l}\text { Patient, } \\
\text { source* }\end{array}$} & \multicolumn{2}{|c|}{ Phenotypic fingerprinting } & \multicolumn{2}{|c|}{ Genotypic fingerprinting } \\
\hline & & Auxotype & Chemotype & Primer 1 & Primer 2 \\
\hline 1 & A & I & B-2 & 1 & 1 \\
\hline 2 & B & II & B-2 & 1 & 1 \\
\hline 3 & B & I & B-2 & 1 & 1 \\
\hline 4 & $\mathrm{C}$ & Il & B-2 & 1 & 1 \\
\hline 5 & $\mathrm{C}$ & III & B-2 & 1 & 1 \\
\hline 6 & $\mathrm{C}$ & I & B-2 & 1 & 1 \\
\hline 7 & $\mathrm{C}$ & IV & B-1 & 1 & 1 \\
\hline 8 & CBS & $\mathrm{V}$ & A & 2 & 2 \\
\hline 9 & CBS & VI & B-2 & 1 & 3 \\
\hline 10 & CBS & II & B-1 & 1 & 3 \\
\hline 11 & CBS & VII & A & 3 & 4 \\
\hline
\end{tabular}

CBS, Centraalbureau voor Schimmelcultures.

${ }^{*}$ See Table 1 for details. 
restriction fragment analysis, a close relationship between strains of $E$. dermatitidis was found [7,8]. By ribotyping the small subunit rDNA, $21 E$. dermatitidis strains could be separated into two clusters [6]. By analysis of RAPD patterns of the 21 strains with four different primers, seven genotypes were found [6]. Three of these strains - two reference CF strains (nos. 8 and 9) and the Japanese strain (no. 11) - were investigated in the present study. In agreement with the results of Uijthof et al. [6], the two CF strains could be separated from each other and from the Japanese strain.

In total, analysis of RAPD patterns obtained by two arbitrary primers revealed four different genotypes in the present study. The identical patterns of the strains isolated from patients from Essen indicated that the patients were colonised by the same genotype but different phenotypes of $E$. dermatitidis. However, the interpretation of RAPD results suffers from some limitations, as strains with identical patterns generated by only a few primers might be different when investigated with more primers or primer combinations [12]. Unfortunately, the combination of the two primers failed to generate reproducible patterns in the PCR.

It is concluded that some of the phenotypic methods used in this study were insufficient for fingerprinting $E$. dermatitidis. Results of assimilation tests seem to be highly variable between different laboratories. Susceptibility patterns, protein and glycoconjugate patterns did not allow strain differentiation of isolates from patients with CF. Discrimination of three clusters was possible by the FAME profiles, but the results were not in agreement with those of the genotypic analysis, which identified four genotypes. Both methods are recommended for typing $E$. dermatitidis.

We thank Mr D. Schmidt for his excellent technical assistance.

\section{References}

1. Matsumoto T, Matsuda T, McGinnis MR, Ajello L. Clinical and mycological spectra of Wangiella dermatitidis infections. Mycoses 1993; 36: 145-155.

2. Kwon-Chung KJ, Bennett, JE. Medical mycology. Phaeohyphomycosis (chromomycosis, phaeosporotrichoris, cerebral chromomycosis). Philadelphia, Lea and Febiger. 1992. 620-677.

3. Haase G, Skopnik H, Groten T, Kusenbach G, Posselt H-G Long-term fungal cultures from sputum of patients with cystic fibrosis. Mycoses 1991; 34: 373-376.
4. Blaschke-Hellmessen R, Lauterbach I, Paul K-D, Tintelnot K, Weissbach G. Nachweis von Exophiala dermatitidis (Kano) de Hoog 1977 bei Septikämie eines Kindes mit akuter lymphatischer Leukämie und bei Patienten mit Mukoviszidose. [of Exophiala dermatitidis (Kano) de Hoog 1977 from a child with septicaemia in acute lymphatic leukemia and from patients with cystic fibrosis.] Mycoses 1994; 37 Suppl 1: 89-96.

5. Kusenbach G, Skopnik H, Haase G, Friedrichs F, Döhmen H. Exophiala dermatitidis pneumonia in cystic fibrosis. Eur $J$ Pediatr 1992; 151: 344-346.

6. Uijthof JMJ, de Hoog GS, de Cock AWAM, Takeo K, Nishimura K. Pathogenicity of strains of the black yeast Exophiala (Wangiella) dermatitidis: an evaluation based on polymerase chain reaction. Mycoses 1994; 37: 235-242.

7. Masuda M, Naka W, Tajima S et al. Deoxyribonucleic acid hybridization studies of Exophiala dermatitidis and Exophiala jeanselmei. Microbiol Immunol 1989; 33: 631-639.

8. Kawasaki M, Ishizaki H, Nishimura K, Miyaji M. Mitochondrial DNA analysis of Exophiala jeanselmei and Exophiala dermatitidis. Mycopathologia 1990; 110: 107-112.

9. de Hoog GS, Guarro J (eds). Atlas of clinical fungi. Centraalbureau voor Schimmelcultures, Barn and Delft, The Netherlands/Universitat Rovira i Vergili, Reus, Spain. 1995: 161.

10. Dermoumi H. In vitro susceptibility of fungal isolates of clinically important specimens to itraconazole, fluconazole and amphotericin B. Chemotherapy 1994; 40: 92-98.

11. Hindler J. Antimicrobial susceptibility testing. In: Isenberg $\mathrm{HD}$ (ed) Clinical microbiology procedures handbook. Washington, DC, American Society for Microbiology. 1992: 5.15.1-5.15.14.

12. Rath P-M, Marggraf G, Dermoumi H, Ansorg R. Use of phenotypic and genotypic fingerprinting methods in the strain identification of Aspergillus fumigatus. Mycoses 1995; 38: 429-434.

13. MIDI, Inc. Sherlock Microbial Identification System operating manual, Version 5. 1995, MIDI Inc., Barksdale Professional Center, Newark, Delaware 19711, USA.

14. Sasser M. Identification of bacteria by gas chromatography of cellular fatty acids. MIDI 1990: Technical Note \#101: 1-7. MIDI Inc., Barksdale Professional Center, Newark, Delaware 19711, USA.

15. Sasser M. "Tracking" a strain using the microbial identification system. MIDI 1990: Technical Note \#102: 1-4. MIDI Inc., Barksdale Professional Center, Newark, Delaware 19711, USA.

16. MIDI Inc. Sherlock library generation, Version 1.0. 1994, Barsdale Professional Center, Newark, Delware 19711, USA

17. Aufauvre-Brown A, Cohen J, Holden DW. Use of randomly amplified polymorphic DNA markers to distinguish isolates of Aspergillus fumigatus. J Clin Microbiol 1992; 30: 2991-2993.

18. Loudon KW, Burnie JP, Coke AP, Matthews RC. Application of polymerase chain reaction to fingerprinting Aspergillus fumigatus by random amplification of polymorphic DNA. $J$ Clin Microbiol 1993; 31: 1117-1121.

19. Espinel-Ingroff A, Shadomy S, Gebhart RJ. In vitro studies with R51, 211 (itraconazole). Antimicrobial Agents Chemother 1984; 26: 5-9.

20. Leonard RB, Mayer J, Sasser M et al. Comparison of MIDI Sherlock System and pulsed-field gel electrophoresis in characterizing strains of methicillin-resistant Staphylococcus aureus from a recent hospital outbreak. J Clin Microbiol 1995; 33: $2723-2727$.

21. Merz WG, Khazan U, Jabra-Rizk MA, Wu L-C, Osterhout GJ, Lehmann PF. Strain delineation and epidemiology of Candida (Clavispora) lusitaniae. J Clin Microbiol 1992; 30: 449-454.

22. Espinel-Ingroff A, McGinnis MR, Pincus DH, Goldson PR, Kerkering TM. Evaluation of the API $20 \mathrm{C}$ yeast identification system for the differentiation of some dermatiaceous fungi. $J$ Clin Microbiol 1989; 27: 2565-2569. 